\title{
Omalizumab inhibits allergen challenge-induced nasal response
}

\author{
G. Hanf, O. Noga, A. O'Connor, G. Kunkel
}

Omalizumab inhibits allergen challenge-induced nasal response. G. Hanf, O. Noga, A. O' Connor, G. Kunkel. (C) ERS Journals Ltd 2004.

ABSTRACT: Elevated serum levels of antigen-specific immunoglobulin (Ig)E are often associated with allergic respiratory diseases. This parallel-group, randomised, doubleblind, placebo-controlled trial was designed to study the influence of omalizumab on the early nasal response to allergen challenge reflected by symptom score and inflammatory marker levels in nasal lavage fluid (NAL).

A total of 23 patients with allergic rhinitis took part in the study, 11 were given placebo and omalizumab was administered subcutaneously in 12. Omalizumab or placebo were given at 2- or 4-week intervals based on a patient's body weight and IgE levels to a total dose of $0.016 \mathrm{mg} \cdot \mathrm{kg}^{-1} \cdot \mathrm{IgE}^{-1}\left(\mathrm{IU} \cdot \mathrm{mL}^{-1}\right)$ every 4 weeks.

Compared to placebo, 16 weeks of treatment with omalizumab significantly inhibited allergen challenge-induced nasal symptoms (median symptom score $7.0-0.5$ versus 7.0-7.0) and inhibited the increase of human serum albumin (median $15.3-0.12 \mathrm{mg} \cdot \mathrm{mL}^{-1}$ versus $8.2-19.7 \mathrm{mg} \cdot \mathrm{mL}^{-1}$ ) in the NAL after allergen challenge. Treatment with omalizumab induced a significant decrease in tumour necrosis factor- $\alpha$ levels in basal NAL, but no change was seen for histamine.

These results indicate that subcutaneously administered monoclonal antiimmunoglobulin-E antibody, omalizumab, inhibits the nasal responses to allergen challenge of patients with allergic rhinitis. Omalizumab may provide a new strategy for the treatment of allergic rhinitis.

Eur Respir J 2004; 23: 414-418.
Allergy and Asthma Clinic, Charité, Humboldt University Berlin, Germany.

Correspondence: G. Kunkel Allergy and Asthma Clinic Charité, Virchow Klinikum Humboldt University Augustenburger Platz 1 13353 Berlin

Germany

Fax: 4930450565902

E-mail: gerald.hanf@charite.de

Keywords: Allergic rhinitis anti-imunoglobulin-E omalizumab

rhuMAb-E25

Received: December 42001

Accepted after revision: September 82003
Allergic rhinitis is a common, increasingly prevalent disease $[1,2]$, associated with elevated serum immunoglobulin (Ig)Elevels. Binding of inhaled allergens to IgE on the surface of basophils and mast cells, with subsequent cross-linkage of IgE and aggregation of high-affinity receptors for $\operatorname{IgE}(\mathrm{Fc} \in \mathrm{RI})$, triggers the release of histamine, leukotrienes and other inflammatory mediators, followed by the onset of allergic symptoms [3]. Current therapeutic strategies include corticosteroids, mast cell stabilisers, antihistamines and immunotherapy. Removal of circulating free IgE by the recombinant humanised monoclonal anti-IgE antibody, omalizumab (Xolair $\mathbb{R}$ ), also referred to as rhuMAb-E25, represents a new approach in the treatment of allergic rhinitis.

Omalizumab is a construct of the murine antibody MAE11 that binds to circulating $\operatorname{IgE}$ on the $\mathrm{Fc}$ site of the $\operatorname{IgE}$ antibody [4]. It does not interact with cell-bound $\operatorname{IgE}$ and therefore does not provoke histamine release from IgEsensitised mast cells [5]. It also inhibits IgE binding to mast cells [6]. In vitro, omalizumab inhibits allergen-induced IgE synthesis by peripheral blood mononuclear leukocytes from atopic volunteers [4]. The efficacy, safety and tolerability, as well as pharmacokinetics and pharmacodynamics of omalizumab, have been assessed in single- and multiple-dose studies [7-10]. In asthmatic subjects, omalizumab attenuates both the early- (EAR) and late-phase responses to inhaled allergen [11-13]. Moreover, omalizumab induced reduction of asthma exacerbations and steroid requirement in allergic asthmatics [14]. In birch pollen-induced seasonal allergic rhinitis, omalizumab reduces concomitant medication and symptoms [7].
As the EAR is mediated by $\operatorname{IgE}$ leading to mast cell or basophil degranulation and release of inflammatory mediators, the aim of this randomised, double-blind, placebo-controlled, parallel-grouped study was to determine if omalizumab has effects on the nasal EAR in subjects suffering from allergic rhinitis. The patients were challenged nasally with the appropriate allergen. As a primary parameter, changes in the nasal symptom score were studied. Reduction of the nasal symptom score would support the clinical effectiveness of omalizumab. Additionally, inflammatory markers in nasal lavage fluid (NAL) were measured. These included histamine, the major mediator of the EAR, human serum albumin (HSA), a marker of vascular permeability, and interleukin (IL)-1 $\beta$ and tumour necrosis factor (TNF)- $\alpha$, cytokines altered in the EAR after nasal allergen challenge.

\section{Methods}

\section{Subjects and study design}

A group of 23 patients suffering from allergic rhinitis participated in the study (table 1). All had at least a 2-yr history of allergic rhinitis and a positive nasal provocation test to the indicated allergen (table 1). Omalizumab or placebo were administered subcutaneously at 2- or 4-week intervals. Body weight and total IgE at screening were used to determine omalizumab administration of at least $0.016 \mathrm{mg} \cdot \mathrm{kg}^{-1} \cdot \mathrm{IgE}^{-1}\left(\mathrm{IU} \cdot \mathrm{mL}^{-1}\right)$ every 4 weeks.

The study design is outlined in table 2 . The study was 
Table 1.-Baseline characteristics of the study subjects

\begin{tabular}{lcc}
\hline Characteristics & Placebo & Omalizumab \\
\hline Subjects n & 11 & 12 \\
Females n & 9 & 8 \\
Males n & 2 & 4 \\
Age yrs & $35(20-60)$ & $36(22-56)$ \\
Allergen & & \\
$\quad$ House dust mite & 3 & 3 \\
$\quad$ Cat dander & 5 & 6 \\
$\quad$ Grass & 2 & 2 \\
$\quad$ Birch & 1 & 1 \\
IgE IU·mL & $210(60-686)$ & $151(36-450)$ \\
\hline
\end{tabular}

Data are present as median (range) unless otherwise stated. ${ }^{\#}$ : allergen used for nasal challenge.

approved by the local Ethic committee and all patients gave informed written consent.

\section{Nasal challenge}

The patients were challenged nasally before treatment and after 16 weeks of treatment with the indicated allergen (table 1). Patients were asymptomatic before the antigen challenge and no antihistamine or local nasal medication was allowed up to 4 weeks prior to challenge.

Prior to the final study protocol, the challenge dose was determined by titration until the subjects developed clinical symptoms. The dose of allergen given after 16 weeks of treatment was identical to the dose given at baseline. The mean dose of allergen needed was 10,000 allergy units.

The nasal challenge was performed as previously described [15]. In brief, four prechallenge nasal lavages were performed with $5 \mathrm{~mL}$ saline solution to wash out pre-existing mediators. After this, the patients were challenged with diluent (albuminbuffered saline; ALK-Scherax, Hamburg, Germany) and nasal lavages were repeated $15 \mathrm{~min}$ later. The allergen (ALK-Scherax) was then inserted into each nostril using a plastic hand-held nebuliser delivering $100 \mu \mathrm{L}$ at each actuation. Another nasal lavage was performed 15 min later. The NAL were placed on ice and frozen at $-70^{\circ} \mathrm{C}$ until analysis. Histamine, albumin, IL- $1 \beta$ and TNF- $\alpha$ were measured in the NAL fluid of the first prewash (pre-challenge), after diluent and after allergen challenge.

\section{Nasal symptom score}

Total symptom scores ranging $0-12$ were obtained from patients following nasal allergen challenge by using four-point scales for sneezing, itching, rhinorrhea and for congestion $(0$ : none; 1: mild; 2: moderate; 3: severe).

\section{Histamine}

For histamine analysis, the NAL was assayed by an automated fluorimetric technique capable of detecting $<0.4 \mathrm{ng} \cdot \mathrm{mL}^{-1}$ histamine [16].

Table 2. - Study design

\begin{tabular}{|c|c|c|c|}
\hline Week & -7 & $-6-0$ & $0-16$ \\
\hline Nasal challenge & & At week 0 & At week 16 \\
\hline Period & Screening & Run-in & Treatment \\
\hline Study treatment & None & None & Omalizumab or placebo \\
\hline
\end{tabular}

\section{Human serum albumin}

HSA was measured by enzyme-linked immunosorbent assay (ELISA). Plates were coated with HSA $\left(5 \mu \mathrm{g} \cdot \mathrm{mL}^{-1}\right)$ overnight at $4{ }^{\circ} \mathrm{C}$ and then blocked with $1 \%$ bovine serum albumin for $1 \mathrm{~h}$. The wells were washed with TRIS buffer and received $100 \mu \mathrm{L}$ of samples and $100 \mu \mathrm{L}$ of mouse monoclonal anti-HSA antibody (1:100,000) (Pierce, Rockford, IL, USA) for $1 \mathrm{~h}$. The wells were washed and $100 \mu \mathrm{L}$ alkaline phosphataseconjugated goat anti-mouse IgG (Dianova, Hamburg, Germany) $(1: 1,000)$ was added for $1 \mathrm{~h}$. The reaction was developed by using p-nitrophenyl phosphate (Sigma, St. Louis, MO, USA) and absorbance was read at $405 \mathrm{~nm}$. The detection limit was $<1 \mathrm{ng} \cdot \mathrm{mL}^{-1}$.

\section{Cytokines}

Concentrations of IL- $1 \beta$ and TNF- $\alpha$ were detected in the NAL using ELISA according to the manufacturer's instructions (Biosource, Camarillo, CA, USA). Detection limits were $<0.19 \mathrm{pg} \cdot \mathrm{mL}^{-1}$ for IL- $\beta$ and $0.09 \mathrm{pg} \cdot \mathrm{mL}^{-1}$ for TNF- $\alpha$.

\section{Statistical analysis}

Comparisons were made between groups using MannWhitney U-test and within groups using Wilcoxon's signedranked test, respectively. Between-group treatment analysis was calculated by percentage change from baseline (pre-study challenge response) after 16 weeks of treatment. A p-value of $<0.05$, using two-tailed tests, was considered statistically significant.

\section{Results}

\section{Clinical response to nasal allergen challenge}

The nasal symptom score of each subject was the same before the two nasal allergen challenges. In the nasal allergen challenge conducted after 16 weeks of treatment, patients treated with omalizumab showed a significantly lower nasal symptom score after challenge (fig. 1, table 3, p<0.001). Furthermore, the omalizumab group symptom score was significantly lower compared to baseline (table $3, \mathrm{p}<0.01$ ).

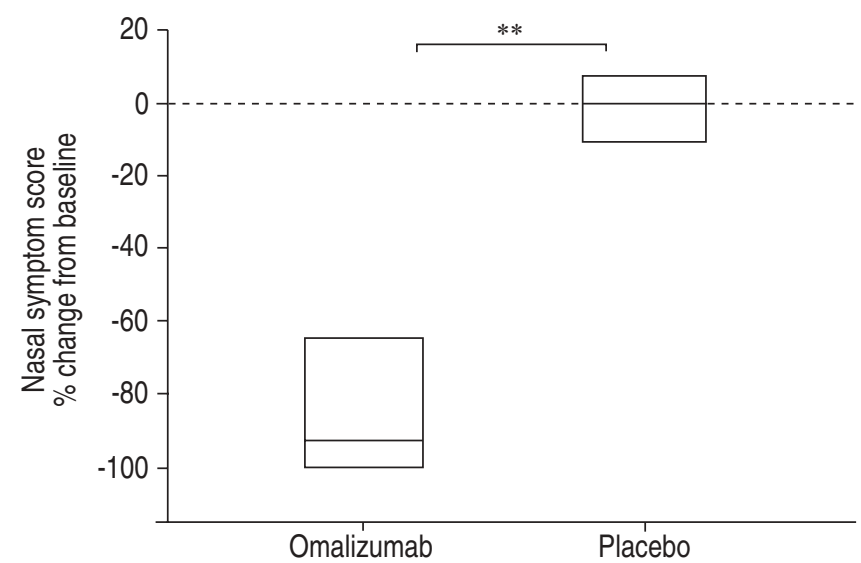

Fig. 1.-Percentage change from baseline of nasal symptom score after nasal allergen challenge of the omalizumab group $(n=12)$ and placebo group $(n=11)$ after 16 weeks of therapy. Data are present as median (25th-75th percentiles). ${ }^{* *}: \mathrm{p}<0.01$. 


\section{Histamine}

There was no significant difference in histamine levels between the pre-challenge NAL collected at baseline or after 16 weeks of treatment in either treatment groups (table 4). After 16 weeks of therapy the increase in histamine in NAL after allergen challenge was significantly lower in the omalizumab group compared to baseline (table $3, \mathrm{p}=0.015$ ). However, no significant difference was seen compared to the placebo group (fig. 2, table 3).

\section{Human serum albumin}

The HSA levels in pre-challenge NAL were not statistically different between treatment groups (table 4). Following 16 weeks of treatment, the increase of HSA levels after allergen challenge were significantly lower in the omalizumab group compared to the placebo group (fig. 3 , table $3, \mathrm{p}<0.01$ ).

\section{Cytokines}

After 16 weeks trial treatment, the pre-challenge NAL showed a significant decrease of TNF- $\alpha$ in the omalizumab group compared to the placebo group (fig. 4, table 4, $\mathrm{p}=0.015)$. There was no detectable statistically significant

Table 3. - Nasal symptom score and increase of histamine and human serum albumin (HSA) after nasal allergen challenge at baseline and after 16 weeks of therapy

\begin{tabular}{lcc}
\hline & Baseline & 16 weeks therapy \\
\hline $\begin{array}{l}\text { Nasal symptom score } \\
\quad\end{array}$ & & \\
$\quad$ Placebo & $7.0(1-12)$ & $7.0(1-11)$ \\
$\quad$ Omalizumab & $7.0(3-10)$ & $0.5(0-8)^{* *, \# \#}$ \\
Histamine increase & & \\
ng.mL & & \\
Placebo & $0.58(0.1-5.76)$ & $0.35(0.01-4.39)$ \\
$\quad$ Omalizumab & $1.17(0.1-6.97)$ & $0.31(0.01-1.58)^{*}$ \\
HSA increase & & \\
$\quad{\mathrm{mg} \cdot \mathrm{mL}^{-1}}_{\text {Placebo }}$ & $8.22(0.03-428.98)$ & $19.73(0.01-107.78)$ \\
$\quad$ Omalizumab & $15.30(0.01-740.44)$ & $0.12(0.01-6.38)^{* *, \# \#}$ \\
\hline
\end{tabular}

Data are presented as median (range). *: $\mathrm{p}<0.05 ; * *: \mathrm{p}<0.01$ versus baseline; ${ }^{\# \#}: \mathrm{p}<0.01$ versus placebo ( $\%$ change from baseline).

Table 4.-Inflammatory markers in nasal lavage fluid of the first prewash at baseline and after 16 weeks of therapy

\begin{tabular}{lll}
\hline & \multicolumn{1}{c}{ Baseline } & 16 weeks therapy \\
\hline $\begin{array}{l}\text { Histamine } \mathrm{ng} \cdot \mathrm{mL}^{-1} \\
\quad \text { Placebo }\end{array}$ & $1.11(0.6-10.61)$ & $1.67(0.44-7.58)$ \\
$\quad$ Omalizumab & $0.93(0-4.3)$ & $1.36(0.43-10.07)$ \\
$\mathrm{HSA} \mathrm{mg} \cdot \mathrm{mL}^{-1}$ & $1.10(0.12-4.01)$ & $1.72(0.86-58.33)$ \\
$\quad$ Placebo & $0.50(0.24-25.43)$ & $2.02(0.30-44.50)$ \\
$\quad$ Omalizumab & $0.21(0-0.86)$ & $0.21(0-1.79)$ \\
$\begin{array}{l}\mathrm{IL}-1 \beta \mathrm{pg} \cdot \mathrm{mL}^{-1} \\
\quad \text { Placebo }\end{array}$ & $0.25(0-1.05)$ & $0.24(0-1.19)$ \\
$\quad$ Omalizumab & & \\
TNF- $\alpha \mathrm{pg} \cdot \mathrm{mL}^{-1}$ & $0.41(0-9.72)$ & $0.60(0.23-6.59)$ \\
$\quad$ Placebo & $0.92(0-6.99)$ & $0.38(0.15-4.85)^{*, \#}$ \\
$\quad$ Omalizumab &
\end{tabular}

Data are presented as median (range). *: p $<0.05$ versus baseline; *: $\mathrm{p}<0.05$ versus placebo ( $\%$ change from baseline). difference in pre-challenge IL-1 $\beta$ levels between both groups (fig. 5, table 4). Following diluent or allergen challenge, TNF$\alpha$ and IL-1 $\beta$ values were not detectable.

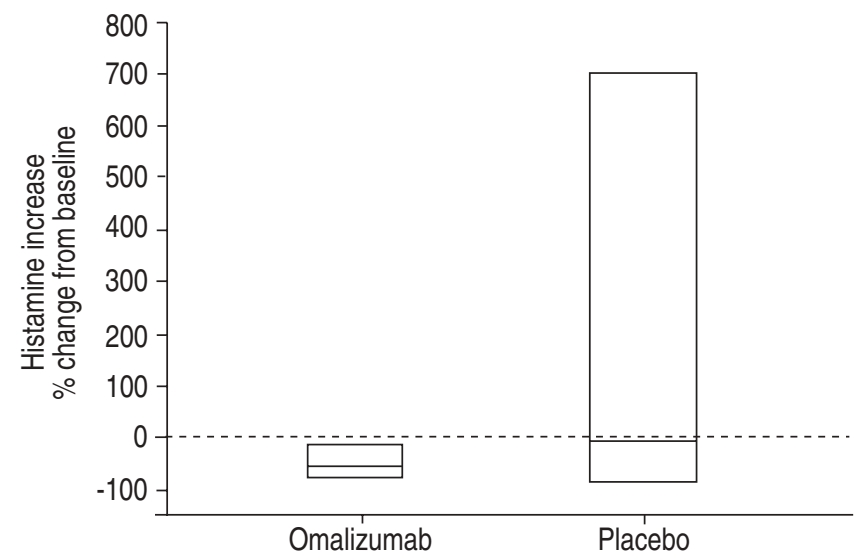

Fig. 2. - Percentage change from baseline of histamine release after nasal allergen challenge of the omalizumab group $(n=12)$ and placebo group $(\mathrm{n}=11)$ after 16 weeks of therapy. Data are present as median (25th-75th percentiles)

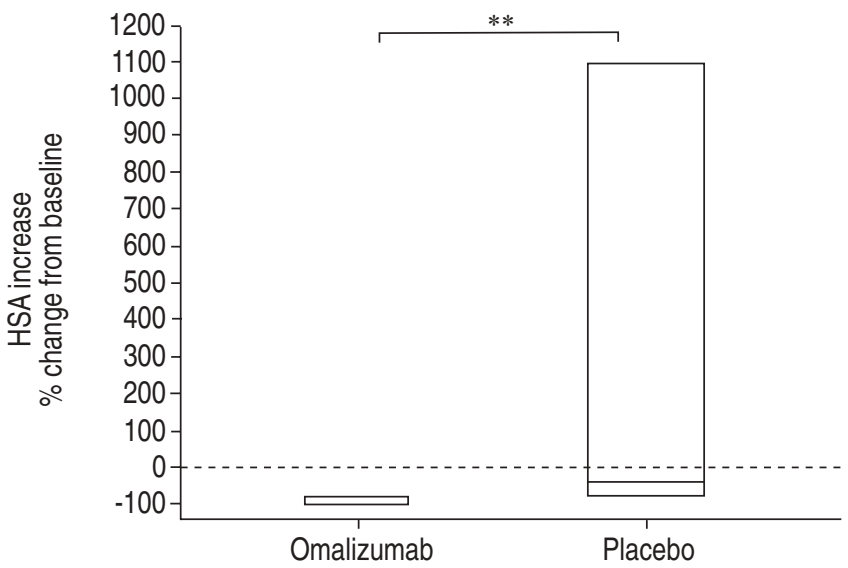

Fig. 3. - Percentage change from baseline of human serum albumin (HSA) release after nasal allergen challenge of the omalizumab group $(\mathrm{n}=12)$ and placebo group $(\mathrm{n}=11)$ after 16 weeks of therapy. Data are present as median (25th-75th percentiles). ${ }^{* *}: \mathrm{p}<0.01$.

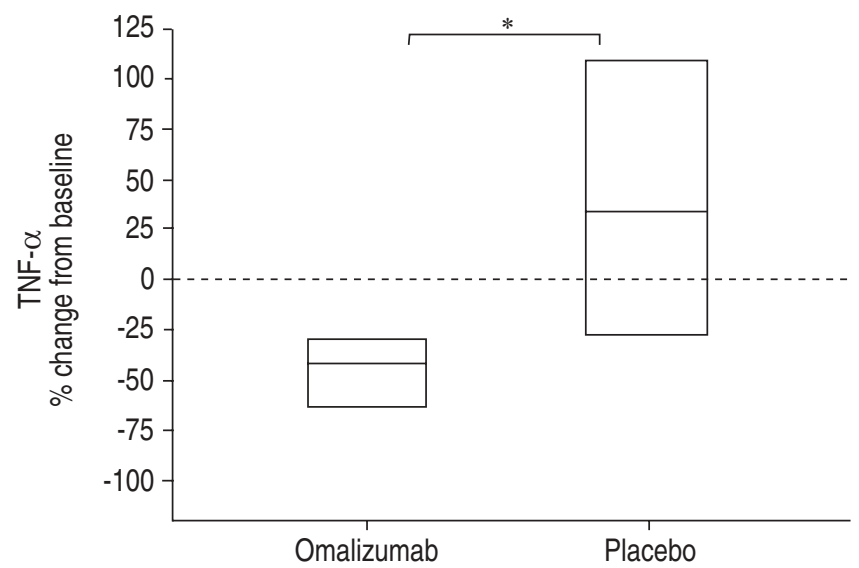

Fig. 4. - Percentage change from baseline in tumour necrosis factor (TNF)- $\alpha$ in pre-challenge nasal lavage fluid of the omalizumab group $(n=12)$ and placebo group $(n=11)$ after 16 weeks of therapy. Data are present as median (25th-75th percentiles). $*$ : $p<0.05$. 


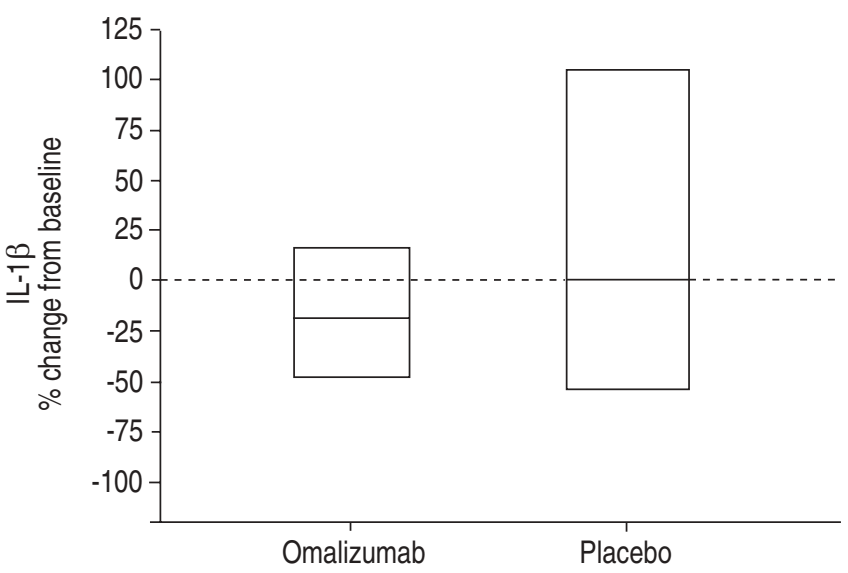

Fig. 5. - Percentage change from baseline in interleukin (IL)-1 $\beta$ in pre-challenge nasal lavage fluid of the omalizumab group $(n=12)$ and placebo group $(\mathrm{n}=11)$ after 16 weeks of therapy. Data are present as median (25th-75th percentiles).

\section{Discussion}

This study demonstrates that treatment with omalizumab, a humanised monoclonal antibody directed against $\operatorname{IgE}$, reduces nasal EAR in subjects with allergic rhinitis.

Omalizumab treatment significantly reduces the nasal symptom score after allergen challenge. This demonstrates the effectiveness of omalizumab and these findings agree with recently published data describing a reduction of concomitant medication and symptoms in birch pollen-induced seasonal allergic rhinitis on treatment with omalizumab [7].

A statistically significant decrease of albumin after allergen challenge was observed in the NAL of omalizumab-treated subjects. Therefore, the effect of omalizumab could be caused, in part, by inhibition of vascular permeability reflected by albumin levels. Increased vascular permeability after allergen challenge is caused by mediators like histamine, kinins, leukotrienes or cytokines [17].

Histamine, stored in mast cells and basophils is the major mediator of acute allergic rhinitis, causing itching, sneezing, congestion and rhinorrhea by increasing vascular permeability, vasodilatation and glandular secretion [17]. Within minutes of allergen exposure, histamine can be measured in nasal lavages [15]. Infusion of omalizumab decreased basophil IgE and FceRI surface density, and Ag-induced basophil histamine release in vitro [18]. Therefore, an omalizumabinduced inhibition of histamine release after allergen challenge was expected. However, no significant difference in histamine release after allergen challenge was found in patients treated with omalizumab versus those receiving placebo. This might be because omlizumab has no effect on histamine release in this model or because of the extensive variation in response to the different allergens used. This indicates that a larger number of subjects should be studied to determine whether the treatment effects are significant or not.

The nose also contains different inflammatory cells that may contribute cytokines to the allergic response [16]. IL-1 $\beta$ and TNF- $\alpha$ levels have been measured $2 \mathrm{~h}$ after allergen challenge in nasal lavage, and their increase corresponded to the rise in neutrophil and eosinophil cell infiltration [19]. In addition, mast cell activation in vitro leads to the release of pro-inflammatory cytokines, including TNF- $\alpha$ and IL-1 $\beta$ [19-21]. IL-1 $\beta$ is also produced by monocytes and macrophages after antigen stimulation, and is an important signal for the activation of resting T-cells [22]. Furthermore, TNF- $\alpha$ and IL-1 $\beta$ are involved in the regulation of allergic inflammatory processes, since both lead to a significant increase in adhesion receptor expression in vitro [20, 23]. Omalizumab also induced a significant decrease in TNF- $\alpha$ levels in the pre-challenge NAL, indicating an anti-inflammatory effect. No change was seen in the placebo group. Postchallenge, however, no detectable amounts of IL- $1 \beta$ or TNF$\alpha$ were found. This could be explained by the additional hypersecretion factor and/or the short time between allergen stimulation and lavage sampling.

The results described here do allow a deeper insight into the mode of action of omalizumab. The binding of omalizumab to circulating IgE leads consequently to a downregulation of $\mathrm{TNF}-\alpha$, and probably to a decrease in the liberation of stored and newly synthesised mediators from target cells (mast cells, basophils and eosinophils). The reduction in TNF- $\alpha$ suggests possible downregulation on a fundamental level, since TNF- $\alpha$ amplifies both immunologic and cellular mechanisms of inflammation.

In conclusion, these findings suggest that the use of the humanised monoclonal anti-immunoglobulin $\mathrm{E}$ antibody omalizumab, administered subcutaneously, inhibits the nasal responses to allergen challenge in subjects with allergic rhinitis. Therefore, omalizumab may provide a new strategy for the treatment of allergic rhinitis.

Acknowledgements. This study was supported by Novartis Pharma GmbH, Nurenberg, Germany.

\section{References}

1. Lundback B. Epidemiology of rhinitis and asthma. Clin Exp Allergy 1998; 28: Suppl. 2, 3-10.

2. Worldwide variation in prevalence of symptoms of asthma, allergic rhinoconjunctivitis, and atopic eczema: ISAAC. The International Study of Asthma and Allergies in Childhood (ISAAC) Steering Committee. Lancet 1998; 351: 1225-1232.

3. Ishizaka T, Ishizaka K. Activation of mast cells for mediator release through IgE receptors. Prog Allergy 1984; 34: 188235

4. Shields RL, Whether WR, Zioncheck K, et al. Inhibition of allergic reactions with antibodies to IgE. Int Arch Allergy Immunol 1995; 107: 308-312.

5. Presta LG, Lahr SJ, Shields RL, et al. Humanization of an antibody directed against IgE. J Immunol 1993; 151: 26232632.

6. Saban R, Haak Frendscho M, Zine M, et al. Human FceRIIgG and humanized anti-IgE monoclonal antibody MaE11 block passive sensitization of human and rhesus monkey lung. J Allergy Clin Immunol 1994; 94: 836-843.

7. Adelroth E, Rak S, Haahtela $\mathrm{T}$, et al. Recombinant humanized $\mathrm{mAb}-\mathrm{E} 25$, an anti-IgE $\mathrm{mAb}$, in birch polleninduced seasonal allergic rhinitis. J Allergy Clin Immunol 2000; 106: 253-259.

8. Casale TB, Bernstein IL, Busse WW, et al. Use of an antiIgE humanized monoclonal antibody in ragweed-induced allergic rhinitis. J Allergy Clin Immunol 1997; 100: 110-121.

9. Fox JA, Hotaling TE, Struble C, Ruppel J, Bates DJ, Schoenhoff MB. Tissue distribution and complex formation with $\operatorname{IgE}$ of an anti-IgE antibody after intravenous administration in cynomolgus monkeys. J Pharmacol Exp Ther 1996; 279: 1000-1008.

10. Milgrom H, Fick RB Jr, Su JQ, et al. Treatment of allergic asthma with monoclonal anti-IgE antibody. rhuMAb-E25 Study Group. N Engl J Med 1999; 341: 1966-1973.

11. Fahy JV, Fleming HE, Wong HH, et al. The effect of an anti-IgE monoclonal antibody on the early- and late-phase responses to allergen inhalation in asthmatic subjects. $\mathrm{Am}$ J Respir Crit Care Med 1997; 155: 1828-1834. 
12. Boulet LP, Chapman KR, Cote J, et al. Inhibitory effects of an anti-IgE antibody E25 on allergen-induced early asthmatic response. Am J Respir Crit Care Med 1997; 155: 1835-1840.

13. Barnes PJ. Anti-IgE antibody therapy for asthma. $N$ Engl J Med 1999; 341: 2006-2008.

14. Solèr M, Matz J, Townley R, et al. The Anti-IgE antibody omalizumab reduces exacerbations and steroid requirement in allergic asthmatics. Eur Respir J 2001; 18: 254-261.

15. Naclerio RM, Meier HL, Kagey Sobotka A, et al. Mediator release after nasal airway challenge with allergen. Am Rev Respir Dis 1983; 128: 597-602.

16. Siraganian RP. Automated histamine release. A method for in vitro allergy diagnosis. Int Arch Allergy Appl Immunol 1975; 49: 108-110.

17. White MV, Kaliner MA. Mediators of allergic rhinitis. J Allergy Clin Immunol 1992; 90: 699-704.

18. Saini SS, MacGlashan DW Jr, Sterbinsky SA, et al. Downregulation of human basophil $\mathrm{IgE}$ and FceRI alpha surface densities and mediator release by anti-IgE-infusions is reversible in vitro and in vivo. $J$ Immunol 1999; 162 : 5624 5630.

19. Plaut M, Pierce JH, Watson CJ, Hanley Hyde J, Nordan RP, Paul WE. Mast cell lines produce lymphokines in response to cross-linkage of FceRI or to calcium ionophores. Nature 1989; 339: 64-67.

20. Gordon JR, Galli SJ. Mast cells as a source of both preformed and immunologically inducible TNF-alpha/ cachectin. Nature 1990; 346: 274-276.

21. Burd PR, Rogers HW, Gordon JR, et al. Interleukin 3-dependent and -independent mast cells stimulated with IgE and antigen express multiple cytokines. J Exp Med 1989; 170: 245-257.

22. Dinalrello CA. Interleukin-1 and its biologically related cytokines. Adv Immunol 1989; 44: 153-176.

23. Bachert C, Wagenmann M, Hauser U. Proinflammatory cytokines: measurement in nasal secretion and induction of adhesion receptor expression. Int Arch Allergy Immunol 1995; 107: 106-108. 